\title{
Effectiveness of Transverse Abdominis Plane Block as a Method of Regional Anaesthesia in Unilateral Inguinal Hernia Repair
}

\author{
Neeta Verma ${ }^{1}$, Krishnendu S², Aruna V Chandak ${ }^{3}$, Amol Singam4, Vijay C Chandak ${ }^{5}$, Vivek Chakole ${ }^{6}$ \\ 1, 2, 3, 4, 5, 6 Department of Anaesthesiology, AVBRH, Jawaharlal Nehru \\ Medical College, Sawangi (Meghe), Wardha, Maharashtra, India.
}

\section{ABSTRACT}

\section{BACKGROUND}

The Transverses Abdominis Plane (TAP) block is a relatively new regional technique which is often used for sensory blockade of the lower abdominal wall mainly for postoperative pain relief. It causes sensory blockade mainly because of injection of local anaesthetic between the internal oblique and the transverse abdominis muscle. TAP block was performed using a blind landmark technique in the lumbar petit triangle. Nowadays USG guided TAP block is being performed in many centers. TAP block is known to improve postoperative pain, reduce the opioid demand, and also reduce the time to rescue analgesia in patients undergoing lower abdominal surgeries. In our study, we have used TAP block as a main anaesthetic technique in patients posted for unilateral inguinal hernia repair under elective conditions. TAP Block in this study was given with $0.5 \%$ bupivacaine. Duration of anaesthesia / analgesia, effectiveness of block, period of block, cardiac stability and haemodynamic stability were studied.

\section{METHODS}

A prospective observational study was conducted on 30 randomly selected individuals posted for elective inguinal hernia repair who belonged to American Society of Anaesthesiologists classification 1 and 2; age group between 20 and 70 years; satisfying all inclusion and exclusion criteria. All the patients received $0.5 \%$ bupivacaine for TAP block, dose not more than $2.5 \mathrm{mg} / \mathrm{Kg}$ body weight.

\section{RESULTS}

We have found that TAP block gives good anaesthesia for patients posted for inguinal hernia repair with good haemodynamic stability. With inj. Bupivacaine $0.5 \%$ having an onset of anaesthesia at about $7.45+/-2.32$ minutes ( $\mathrm{p}$ value $<0.001$ ). The block was complete and effectively elevated nociceptive stimuli. The block lasted till the end of surgery in all cases, with no complications.

\section{CONCLUSIONS}

TAP block other than being the main anaesthetic technique for lower abdominal surgery, also provides good post-operative analgesia with minimal post-operative analgesic requirement with less haemodynamic variations.

\section{KEY WORDS}

Tap Block, Regional Anaesthesia, Post-Operative Analgesia, Lower Abdominal Surgeries, Inguinal Hernia, Landmark Technique
Corresponding Author:

Dr. Krishnendu $S$.

Department of Anaesthesiology, AVBRH, Jawaharlal Nehru Medical College, Sawangi (Meghe), Wardha, Maharastra, India.

E-mail: krishnendushiva@gmail.com

DOI: $10.14260 / j e m d s / 2020 / 680$

How to Cite This Article:

Verma N, Krishnendu S, Chandak AV, et al. Effectiveness of transverse abdominis plane block as a method of regional anaesthesia in unilateral inguinal hernia repair. J Evolution Med Dent Sci 2020;9(42):30973101, DOI: 10.14260/jemds/2020/680

Submission 13-07-2020,

Peer Review 07-09-2020

Acceptance 14-09-2020,

Published 19-10-2020.

Copyright (c) 2020 Neeta Verma, et al. This is an open access article distributed under Creative Commons Attribution License [Attribution 4.0 International (CC BY 4.0)] 


\section{BACKGROUND}

The transverse abdominal plane block (TAP) is a technique of regional anaesthesia that provides analgesia to the skin and muscles of the anterior abdominal wall and the parietal peritoneum. ${ }^{1}$ TAP block has been used for any surgeries involving lower abdominal wall like, caesarean section, hernia repair, appendectomy, etc. A single dose of local anaesthetic dose can provide wide range of sensory block. This block can be performed unilaterally or bilaterally especially when the skin incision is expected to cross the midline.

Open inguinal hernia is a frequently performed procedure in male and female patients of all age groups. The anaesthetic techniques may vary from spinal anaesthesia, general anaesthesia, local infiltration blocks or inguinal field block. TAP block has relatively less side effects compared to spinal anaesthesia as well as general anaesthesia.

Since it has been established, that TAP block has undergone several modifications were it is now emphasised its use in variety of surgical procedure. Even though this procedure is relatively safe with high success rate and with less complication TAP block in current clinical practice remains unused.

TAP block is mainly associated with muscles of anterolateral abdominal wall, they are rectus abdominis, transversus abdominis, internal oblique and external oblique. Rectus abdominis which runs in the midline is separated by linea alba. Transversus abdominis, internal oblique and external oblique are located laterally. Above three muscles are located laterally from deep to superficial and they terminate medially as an aponeurosis called the linea semilunaris, lateral to rectus abdominalis. Local anaesthetic is injected above transversus abdominis since TAP plexuses lie above it.

The subcostal approach of TAP block will block sensory supply innervated by T6 - T9 whereas mid axillary line approach between thoracic cage and the iliac crest and between internal oblique and transverse abdominis muscle will ideally block T10 - T11 and the subcostal nerve T12. Lateral TAP block will not cover L1 segmental nerve. So to block L1 anterior TAP block medial to the anterior superior iliac spine is required. Posterior approach to TAB block is via 'triangle of petit 'Since the thoracolumbar nerves originating from the T6 to L1 spinal roots run into this plane and supply sensory nerves to the anterolateral abdominal wall, ${ }^{2}$ the local anaesthetic spread in this plane can block the neural afferents and provide analgesia to the anterolateral abdominal wall.

The transverse abdominus plane (TAP) is given in the layer between the transverse abdominis muscles and internal oblique muscle ${ }^{7}$. After a perception of loss of resistance local anaesthetic is injected between external oblique and internal oblique muscle and the transversus abdominis muscle.2,3 TAP block is used as one of the component of multi model analgesia post operatively, but it is not used as a only source of anaesthesia for inguinal repair.

Complications associated with TAP blocks are less. Theoretically it is said that if local anaesthetic sweep along the transversalis fascia it can cause femoral nerve block. Very poor technique can cause injury to intestine, liver or spleen. ${ }^{15}$

In our study, we tried to explore the anaesthetic and analgesic efficacy, cardiovascular stability, and postoperative analgesia and perioperative complications of TAP block using $0.5 \%$ bupivacaine for unilateral hernioplasty.

\section{METHODS}

After local Ethical Committee clearance and getting patients written informed consent, of American Society of Anaesthesiologist physical status I and II, 30 patients of either gender, undergoing elective unilateral open inguinal hernia repair, age group not less than or equal to 20 and not more than or equal to 70, were enrolled for the study. Patients with multiple hernial repair, known allergy to local anaesthetic, bilateral inguinal hernia, and obstructed, strangulated hernia were incision site is expected to extend beyond midline, patients who have undergone previous surgeries, patients with block site infections, patients with any bleeding disorders, coagulopathy are excluded from study.

Sample size was calculated using OpenEpi application, assuming duration of analgesia as 320 min keeping power at $80 \%$ and confidence interval at $95 \%(\alpha=0.05$ and $\beta=0.2), 25$ patients were required for the study sample, considering the possible drop outs, 30 individuals of both sex were included in the study.

All patients received a preoperative counselling on the nature of the study and the procedure involved. All the surgeries were performed by 4 different surgeons of our institute. Drug used in this study was $0.5 \%$ bupivacaine.

\section{Technique}

All patients were instructed about the procedure. Intravenous access was secured with 18G cannula and ringer lactate infusion started for all patients on arrival in the OT. Standard monitoring protocol comprising of electrocardiography, pulse-oximetry and non-invasive blood pressure was followed for all patients.

With the help of Mc Donnell landmark technique TAP block is given. ${ }^{3}$ The anatomical landmarks were used to plot the triangle of petit. It is bounded anteriorly by external oblique muscle, posteriorly by the latissimus dorsi and inferiorly by the iliac crest.

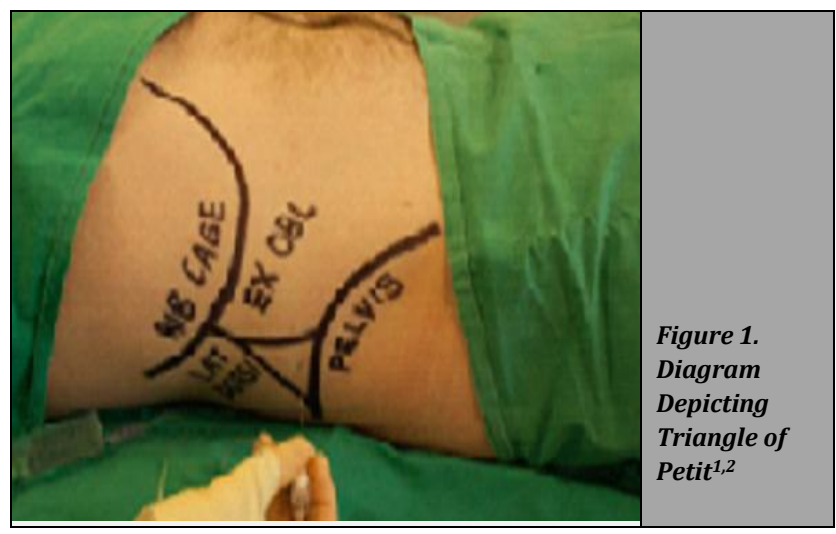

Perpendicular to the skin bevelled and short needle which is usually used for regional block is inserted and was progressed until a $1^{\text {st }}$ pop was felt. Pop here is a feeling of give away when we pierce facia of external oblique muscle. The needle was further progressed until a $2^{\text {nd }}$ pop was felt. This $2^{\text {nd }}$ pop feeling indicates that the internal oblique muscle facial extension is pierced. Bupivacaine 0.5 per cent $20 \mathrm{ml}$ is given after negative aspiration to prevent needle tip malposition. 
Drug is injected slowly, total dose should not exceed $2.5 \mathrm{mg} /$ $\mathrm{Kg}$ which is the maximum safe dose of local anaesthetic. ${ }^{14}$

Time period taken for sensory block onset was measured as the time difference from stopping local anaesthetic injection to loss of sensation above the injected site. Time period taken for complete sensory and motor blockade was recorded. haemodynamic parameters were recorded preoperatively and every 15 minutes intraoperatively, until the end of surgery. Postoperatively parameters were recorded every 2 hourly, until the first rescue analgesia was required. VAS score was also recorded at the time of rescue analgesia.

\section{Statistical Analysis}

All the recorded parameters were analyzed using SPSS version 24.0 software. Students' t-test was used for demographic data analysis. Continuous measurement results are shown on average $+/-$ SD and categorical measurement results are shown in percentages in this study for the level of analysis $p=$ 0.05 and a p-value less than 0.05 was considered statistically significant.

\section{RESULTS}

30 patients posted for elective unilateral inguinal hernia were recruited into this study. Demographic characters like gender, age, weight in kilogram were described in (Table 1) Intraoperative parameters of the patients are summarized in the observation table. Time taken for onset of analgesia and the total duration of surgery was recorded in minutes. (Table 2). Patients were haemodynamically stable throughout. Heart rate, systolic blood pressure, diastolic blood pressure was recorded in pre-operative period, after block, and at 15, 30, 45, $60,75,90,105$ mins, the mean and standard deviation of these values are provided in table 3 and table 4 . The intraoperative period block was successful in all patients and no supplementation of anaesthesia was required during surgery.

\begin{tabular}{|c|c|c|c|}
\hline \multicolumn{2}{|c|}{ Description } & & $\%$ \\
\hline \multicolumn{2}{|c|}{ Number of Observations } & 30 & \\
\hline \multirow{2}{*}{ Gender } & Male & 19 & $63 \%$ \\
\hline & Female & 11 & $37 \%$ \\
\hline \multirow{2}{*}{ Age } & Mean & \multirow{2}{*}{\multicolumn{2}{|c|}{$\begin{array}{l}47.8 \\
8.52\end{array}$}} \\
\hline & Standard Deviation & & \\
\hline \multirow{3}{*}{ Weight (in kgs) } & Mean & \multirow{2}{*}{\multicolumn{2}{|c|}{$\begin{array}{c}61.66 \\
6.35 \\
\end{array}$}} \\
\hline & Standard Deviation & & \\
\hline & \multicolumn{3}{|c|}{ Table 1. Demographic Profile } \\
\hline
\end{tabular}

\begin{tabular}{|cc|}
\hline Description & (Avg. \pm SD) \\
\hline Time Taken for Onset of Block (mins) & $7.45 \pm 2.32$ \\
Time Taken for Complete Block (mins) & $45.23 \pm 5.02$ \\
Duration of Surgery (mins) & $91.46 \pm 5.60$ \\
\hline Table 2. Time Taken for Onset of Analgesia \\
and Duration of Surgery
\end{tabular}

\begin{tabular}{|cc|}
\hline & \\
\hline Heart Rate (Beats / Min ) & (Mean \pm SD) \\
Base Line (Pre-Op) & $77.54 \pm 8.04$ ) \\
Initial (After Block) & $82.32 \pm 7.89$ ) \\
$15 \mathrm{~min}$ & $83.12 \pm 8.11$ \\
$30 \mathrm{~min}$ & $81.29 \pm 7.92$ \\
$45 \mathrm{~min}$ & $80.99 \pm 7.64$ \\
$60 \mathrm{~min}$ & $79.84 \pm 5,78$ \\
$75 \mathrm{~min}$ & $80.27 \pm 7.39$ \\
$90 \mathrm{~min}$ & $81.53 \pm 6.88$ \\
$105 \mathrm{~min}$ & $81.97 \pm 6.12$ \\
\hline Table 3. Haemodynamic Parameters - Heart Rate \\
\hline
\end{tabular}

No intra and postoperative complications were observed. With injection bupivacaine $0.5 \%$ having an onset of anaesthesia at about $7.45+/-2.32$ minutes p value $<0.001$. the block was complete and effectively elevated nociceptive stimuli in $93 \%$ cases. The block lasted till the end of surgery in all cases.

\begin{tabular}{|cccc|}
\hline $\begin{array}{c}\text { Systolic BP } \\
\text { (mmHg) }\end{array}$ & (Mean \pm SD) & $\begin{array}{c}\text { Diastolic BP } \\
\text { (mmHg) }\end{array}$ & (Mean \pm SD) \\
$\begin{array}{c}\text { Base Line (Pre- } \\
\text { op) }\end{array}$ & $119.45 \pm 22.04$ & Base line (Pre-op) & $82.76 \pm 8.04$ \\
$\begin{array}{c}\text { Initial (After } \\
\text { Block) }\end{array}$ & $123.62 \pm 7.89$ & Initial (After Block) & $80.32 \pm 6.89$ \\
$15 \mathrm{~min}$ & $127.83 \pm 6.51$ & $15 \mathrm{~min}$ & $78.92 \pm 7.11$ \\
$30 \mathrm{~min}$ & $125.19 \pm 4.92$ & $30 \mathrm{~min}$ & $79.45 \pm 5.72$ \\
$45 \mathrm{~min}$ & $124.00 \pm 5.34$ & $45 \mathrm{~min}$ & $80.19 \pm 4.94$ \\
$60 \mathrm{~min}$ & $126.34 \pm 4.04$ & $60 \mathrm{~min}$ & $81.34 \pm 5.78$ \\
$75 \mathrm{~min}$ & $125.27 \pm 4.56$ & $75 \mathrm{~min}$ & $80.27 \pm 6.00$ \\
$90 \mathrm{~min}$ & $126.63 \pm 5.18$ & $90 \mathrm{~min}$ & $78.93 \pm 4.88$ \\
$105 \mathrm{~min}$ & $125.97 \pm 6.12$ & $105 \mathrm{~min}$ & $80.01 \pm 5.49$ \\
\hline \multicolumn{4}{|c|}{ Table 4. Haemodynamic Parameters - Blood Pressure } \\
\hline \multicolumn{4}{|c}{} \\
\hline
\end{tabular}

\section{DISCUSSION}

Blocks of abdominal fields were described back in 1993. Rafi identified the TAP block for the first time in 2001. ${ }^{5}$ The TAP block is a simple and effective analgesic technique, which is effective for surgical procedure where parietal peritoneum is considered as major component of postoperative pain. Complication associated with TAP block is very rare. TAP block can be given when neuraxial technique is contraindicated or can be used as a part of multimodal pain regimen. ${ }^{16}$

Rafi presented TAP block as a streamlined abdominal field block with a focused single-shot anaesthetic delivery to the transverse abdominal plane, a location crossed by related nerve branch ${ }^{5}$. This was a major change from previous methods involving multiple injections. TAP block can be given as a sole anaesthetic technique or as multimodal approach or can be given as rescue analgesia in post-operative room for pain relief, this will reduce opioid consumption in the first 24 - $48 \mathrm{hrs}$ post operatively. ${ }^{10,15}$

Short operating procedures in which the parietal peritoneum is an important component of postoperative pain, the TAP block is easily achieved and provides effective analgesia. ${ }^{1}$ Although few research on the TAP block have been performed as a single anaesthetic technique for inguinal hernia repair in emergencies, the available literature is much less successful in elective inguinal hernia repair.4,8 Therefore, this research was undertaken to study its effectiveness as a single anaesthetic agent for unilateral repair of inguinal hernia

John G. Laffey in 2007 studied the TAP block for its analgesic efficacy after caesarean section using $1.5 \mathrm{mg} / \mathrm{Kg}$ of ropivacaine and found to be effective in post caesarean delivery analgesia. ${ }^{9}$ Muhammed Rafay SameemSiddiqui et al in 2011 conducted a meta-analysis on the clinical effectiveness of transversus abdominis plane block and found TAP block reduces the need for postoperative opioid use, it increases the time first request for further analgesia 6 .

C. Aveline and al. (2011) in their study, $0.5 \%$ levobupivacaine was used for day care open inguinal hernia repair in the TAP block and found to be an alternative anaesthesia technique. They also concluded that the TAP block directed by USG provides better results than the blind technique. 8,12 
Murthy et al. In a comparative review. By landmark procedure, using 0.5 percent bupivacaine and 0.75 percent ropivacaine for TAP block in 2016, they found it to be an efficient anaesthesia procedure for open inguinal hernia repair. ${ }^{11}$

Mukhtar and Khattak ${ }^{16}$ reported a significant reduction in the intraoperative morphine consumption following preincisional TAP block for renal transplant recipients. ${ }^{17}$ Most anaesthetists used various drugs such as 0.5 per cent bupivacaine, 0.5 per cent L-bupivacaine, 1.5 per cent mepivacaine, 0.75 per cent ropivacaine in their separate studies and found that TAP block can be used as an alternative technique for postoperative pain relief in patients undergoing lower abdominal surgery, especially in patients with multiple comorbidities. And it is also found that USG TAP block provides better results than blind technique. ${ }^{13}$ There is no much evidence supporting any particular Local anaesthetic for TAP block, local anaesthetic ranging from 8 - $30 \mathrm{ml}$ have been used with various success rate. ${ }^{18}$ Sinha S studied in 2016 comparing the relative analgesic efficacy of bupivacaine and ropivacaine for post-operative pain using USG guided TAP block in laparoscopic cholecystectomies, they concluded that for the immediate post -operative pain ropivacaine provided better pain relief compared to bupivacaine in terms of within $1 \mathrm{hr}$ of surgery, but both showed similar analgesic effect in 24 hrs post-surgery. ${ }^{19}$ Ammar as in 2012 studied the adjuvants, dexamethasone and dexmedetomidine to bupivacaine on transversus abdominis plane block and found that, there is prolongation of duration of the block, and decreased incidence of post-operative nausea and vomiting 20,21

TAP block was implemented in our study using the blind landmark technique described by Mc Donnell etal. From 2007. Patients of both sexes were included for the study. There was no statistically significant difference in the demographic characteristics of the patients. We used bupivacaine at 0.5 percent and found that the onset of anaesthesia to be around $7.45+/-2.32$ minutes ( $\mathrm{p}$ value $<0.001$ ). Time taken for full block was $45.23+/-5.02$ minutes (p value $<0.001$ ). Patients were both intra and postoperatively haemodynamically stable, without any side effects.

\section{CONCLUSIONS}

TAP block offers excellent anaesthesia with haemodynamic stability for inguinal hernia repair, without any perioperative complications. TAP block is safe to use for repairing inguinal hernia.

\section{Limitations}

Double-pop blind technique was applied to identify the TAP. The block's accuracy would have been improved if it were carried out using an ultrasound-guided technique which is an alternative technique commonly practiced.

Data sharing statement provided by the authors is available with the full text of this article at jemds.com.

Financial or other competing interests: None.

Disclosure forms provided by the authors are available with the full text of this article at jemds.com.

\section{REFERENCES}

[1] Jankovic ZB, du Feu FM, McConnell P. An anatomical study of transversus abdominis plane block; location of the lumbar triangle of petit and adjacent nerves. Anaesth Analg 2009;109;(3);981-5.

[2] Rozen WM, Tran TMN, Ashton MW, et al. Refining the course of the thoracolumbar nerves: a new understanding of the innervation of the anterior abdominal wall. Clin Anat 2008;21(4):325-33.

[3] McDonnell JG, O’Donnell B, Curley G, et al. The analgesic efficacy of transversus abdominis plane block after abdominal surgery; a prospective randomized controlled trial. Anaesth Analg 2007;104(1):193-7.

[4] Petersen PL, Mathiesen O, Stjernholm P, et al. The effect of transversus abdominis plane block or local anaesthetic infiltration in inguinal hernia repair - a randomized clinical trial. Eur J Anaesthesiol 2013;30(7):415-21.

[5] Rafi AN. Abdominal field block; a new approach via lumbar triangle. Anaesthesia 2001;56(10);1024-6.

[6] Siddiqui MR, Sajid MS, Uncles DR, Cheek L, Baig MK. A meta-analysis on the clinical effectiveness of transversus abdominis plane block. Journal of clinical anaesthesia. 2011 Feb 1;23(1):7-14.

[7] Carney J, Lane J, Quondamatteeo F, et al. Defining the limits and the spread beyond the TAP block- radiological and anatomical study. Reg Anaesth Pain Med 2008;33 (suppl 1);181.

[8] Aveline C, Le Hetet H, Le Roux A, et al. Comparison between ultrasound guided transverses abdominis plane and conventional ilioinguinal/iliohypogastric nerve blocks for day- case open inguinal hernia repair. $\mathrm{Br}$ J Anaesth 2010;106(3):380-6.

[9] Laffey JG, McDonnell JG, O'Donnell B, et al. Transverse abdominis plane block. Anaesth Analg 2007;105;883.

[10] Siddiqui MRS, Sajid MS. Uncles DR, Check L, Baig MK, “A meta ananlysis on the clinincal effectiveness of TAP block" Journal Of Clinical Anaesthesia 2011:23(1):121-9.

[11] Venkatesh Murthy KT. (2019) Transversus Abdominis Plane (TAP) Block as a Sole Anaesthetic for Inguinal Hernia Repair and for Postoperative Pain Management in Patients Undergoing Lower Abdominal Surgeries. Int J Anaesth Res, 2(1): 35-38.

[12] Young MJ, Gorlin AW, Modest VE, et al. Clinical implications of transversus abdominis plane block in adults. Anaesthesiol Res Pract 2012;2012:731645.

[13] Hebbard P, Fujiwara Y, Shibata Y, et al. Ultrasound-guided transversus abdominis plane (TAP) block. Anaesth Intensive Care 2007;35(4):616-7.

[14] O'Donnell BD, McDonnell JG, McShane AJ. The transversus abdominis plane (TAP) block in open retropubic prostatectomy. Reg Anaesth Pain Med 2006;31(1):91.

[15] Bhaskar SB, Balasubramanya $H$. The transversus abdominis plane block: case for optimal tap. Indian J Anaesth 2016;60(4):231-3.

[16] Venkatraman R, Abhinaya RJ, Sakthivel A, et al. Efficacy of ultrasound-guided transversus abdominis plane block for postoperative analgesia in patients undergoing inguinal hernia repair. Local Reg Anaesth 2016;9:7-12. 
[17] Mukhtar KA, Khattak I. Transversus abdominis plane block for renal transplant recipients. $\mathrm{Br} \mathrm{J}$ Anaesth 2010;104(5):663-4.

[18] Young MJ, Gorlin AW, Modest VE, et al. Clinical implications of the transversus abdominis plane block in adults. Anaesthesiol Res Pract 2012;2012:731645

[19] Sinha S, Palta S, Saroa R, et al. Comparison of ultrasoundguided transversus abdominis plane block with bupivacaine and ropivacaine as adjuncts for postoperative analgesia in laparoscopic cholecystectomies. Indian J Anaesth 2016;60(4):264-9.
[20] Ammar AS, Mahmoud KM. Effect of adding dexamethasone to bupivacaine on transversus abdominis plane block for abdominal hysterectomy: a prospective randomized controlled trial. Saudi J Anaesth 2012;6(3):229-33.

[21] Almarakbi WA, Kaki AM. Addition of dexmedetomidine to bupivacaine in transversus abdominis plane block potentiates post-operative pain relief among abdominal hysterectomy patients: a prospective randomized controlled trial. Saudi J Anaesth 2014;8(2):161-6. 